\title{
Progress Report on Alloy 617 Notched Specimen Testing
}

Project No.(s) 23747, 29412

Michael McMurtrey

Richard Wright

Thomas Lillo

Douglas Smith

The INL is a

U.S. Department of Energy

National Laboratory

operated by

Battelle Energy Alliance

\section{August 2016}
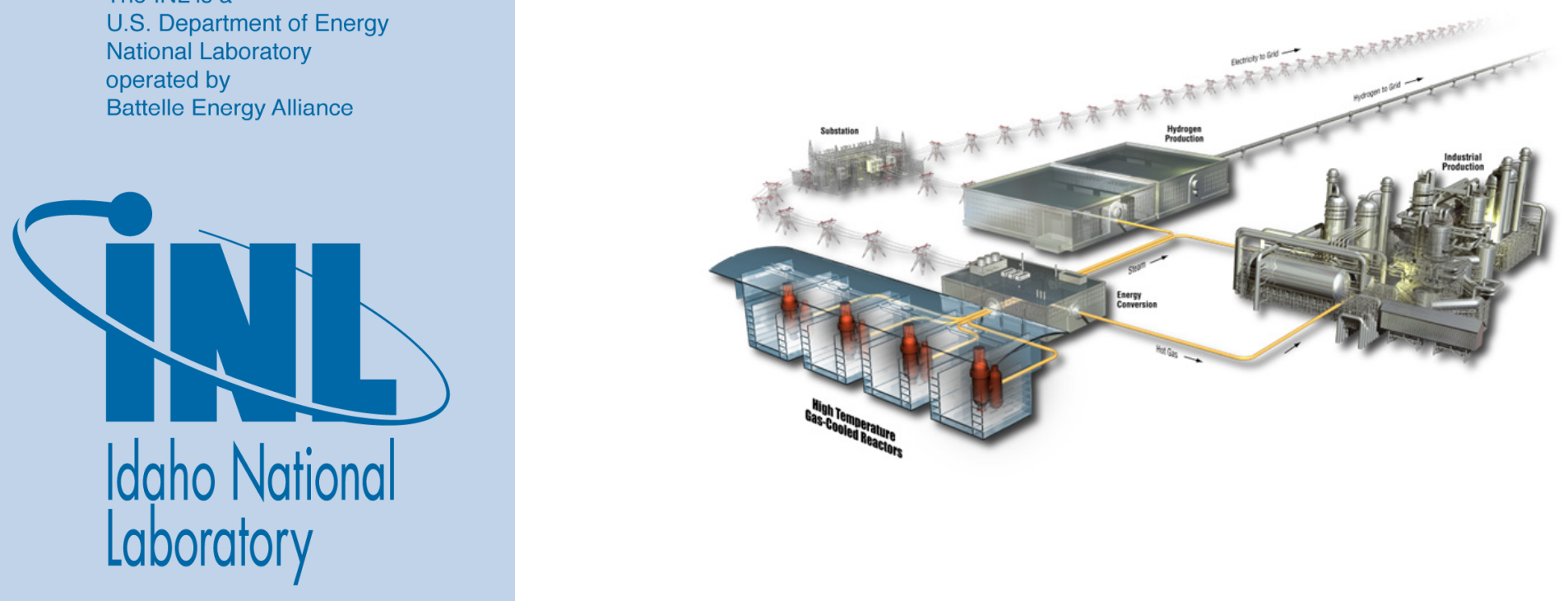


\section{DISCLAIMER}

This information was prepared as an account of work sponsored by an agency of the U.S. Government. Neither the U.S. Government nor any agency thereof, nor any of their employees, makes any warranty, expressed or implied, or assumes any legal liability or responsibility for the accuracy, completeness, or usefulness, of any information, apparatus, product, or process disclosed, or represents that its use would not infringe privately owned rights. References herein to any specific commercial product, process, or service by trade name, trade mark, manufacturer, or otherwise, does not necessarily constitute or imply its endorsement, recommendation, or favoring by the U.S. Government or any agency thereof. The views and opinions of authors expressed herein do not necessarily state or reflect those of the U.S. Government or any agency thereof. 
INL/EXT-16-39683

Revision 0

\title{
Progress Report on Alloy 617 Notched Specimen Testing
}

\author{
Michael McMurtrey \\ Richard Wright \\ Thomas Lillo \\ Douglas Smith
}

August 2016

\begin{abstract}
Idaho National Laboratory
INL ART TDO Program

Idaho Falls, Idaho 83415
\end{abstract}

http://www.inl.gov

Prepared for the

U.S. Department of Energy

Office of Nuclear Energy

Under DOE Idaho Operations Office

Contract DE-AC07-05ID14517 



\title{
INL ART TDO Program
}

\section{Progress Report on Alloy 617 Notched Specimen Testing}

\author{
INL/EXT-16-39683 \\ Revision 0
}

August 2016

Technical Reviewer: (Confirmation of mathematical accuracy, and correctness of data and appropriateness of assumptions.)
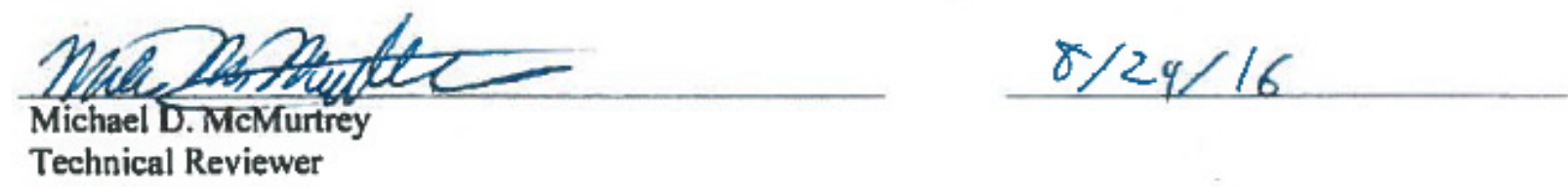

Technical Reviewer

\section{Approved by:}
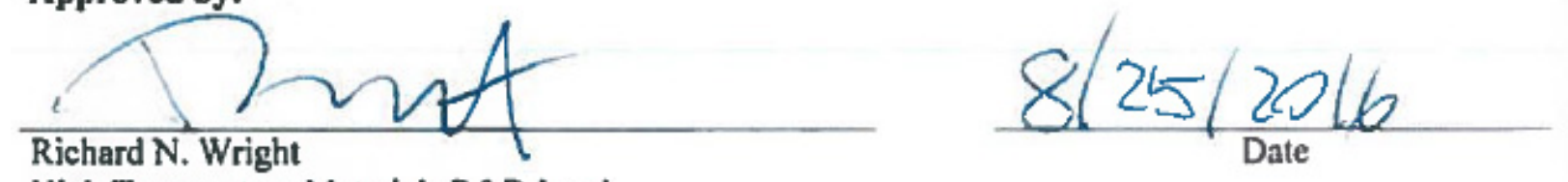

High Temperature Materials R\&D Lead

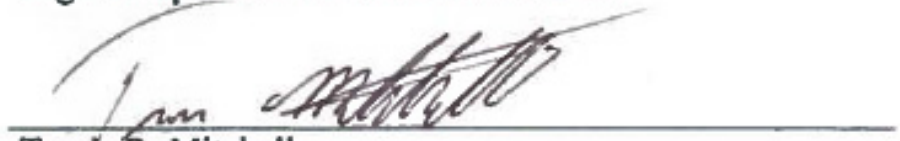

Travis R. Mitchell

INL ART TDO Relationship Manager
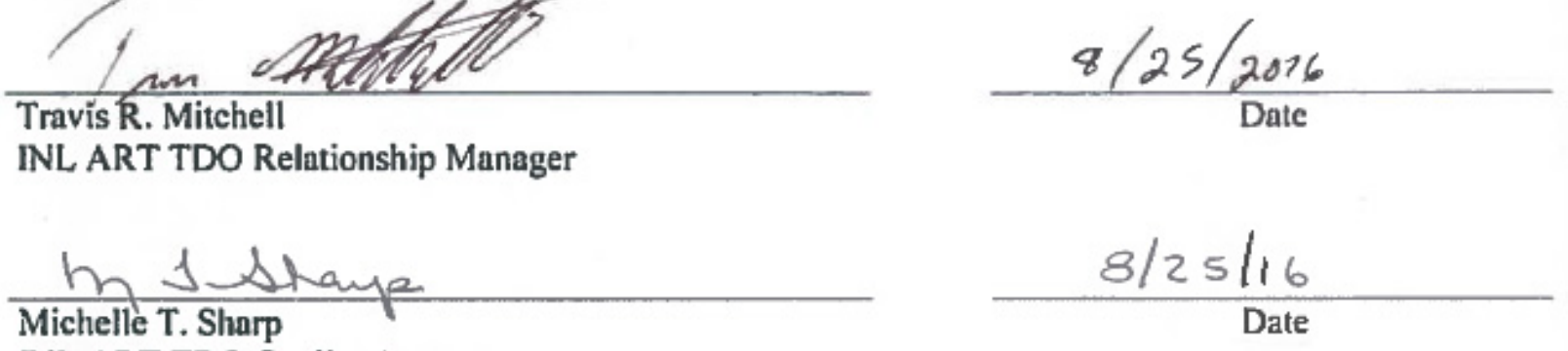

INL ART TDO Quality Assurance

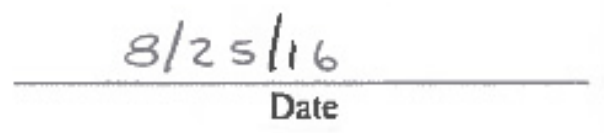





\begin{abstract}
Creep behavior of Alloy 617 has been extensively characterized to support the development of a draft Code Case to qualify Alloy 617 in Section III division 5 of the ASME Boiler and Pressure Vessel Code. This will allow use of Alloy 617 in construction of nuclear reactor components at elevated temperatures and longer periods of time (up to $950^{\circ} \mathrm{C}$ and 100,000 hours). Prior to actual use, additional concerns not considered in the ASME code need to be addressed. Code Cases are based largely on uniaxial testing of smooth gage specimens. In service conditions, components will generally be under multi-axial loading. There is also the concern of the behavior at discontinuities, such as threaded components.

To address the concerns of multi-axial creep behavior and at geometric discontinuities, notched specimens have been designed to create conditions representative of the states that service components experience. Two general notch geometries have been used for these series of tests: U-notch and V-notch specimens. The notches produce a tri-axial stress state, though not uniform across the specimen. Characterization of the creep behavior of the U-notch specimens and the creep rupture behavior of the $\mathrm{V}$-notch specimens provides a good approximation of the behavior expected of actual components.

Preliminary testing and analysis have been completed and are reported in this document. This includes results from V-notch specimens tested at $900^{\circ} \mathrm{C}$ and $800^{\circ} \mathrm{C}$. Failure occurred in the smooth gage section of the specimen rather than at the root of the notch, though some damage was present at the root of the notch, where initial stress was highest. This indicates notch strengthening behavior in this material at these temperatures.
\end{abstract}




\section{CONTENTS}

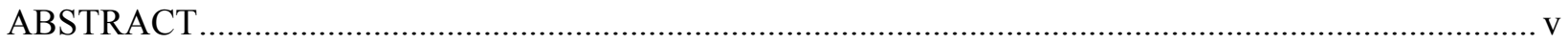

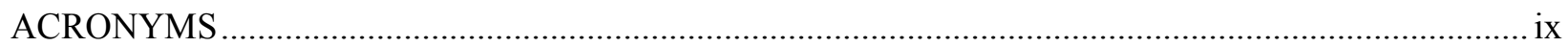

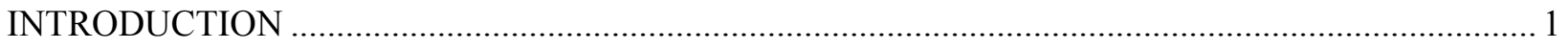

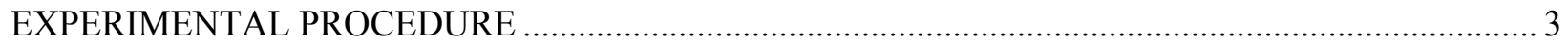

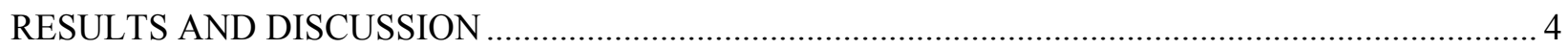

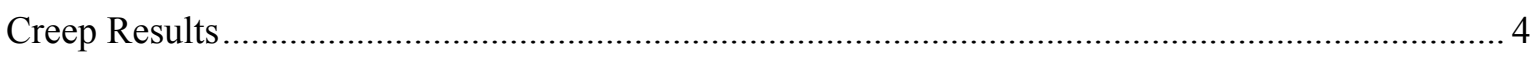

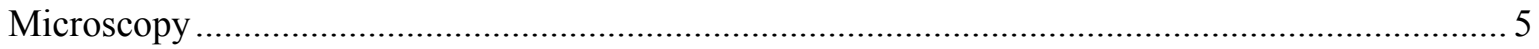

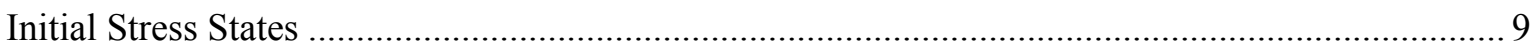

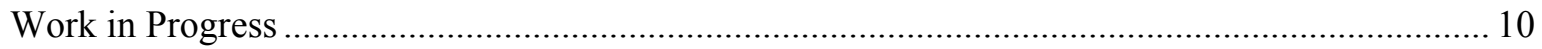

CONCLUSIONS

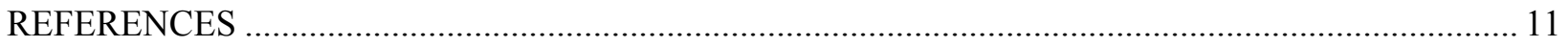

\section{FIGURES}

Figure 1. Creep rupture specimen commonly used during alloy development, featuring both a

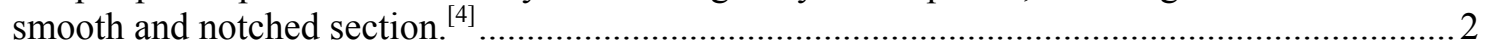

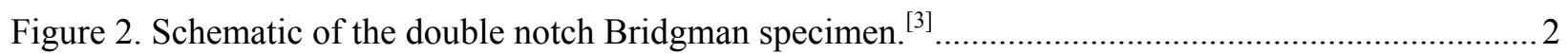

Figure 3. Schematic of the Bridgeman notches with varying $d_{n o} / r_{n o}$ ratios, all of which have a

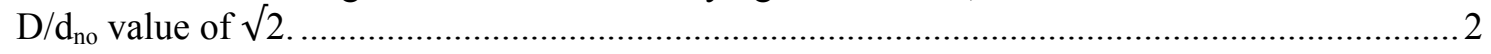

Figure 4. Actual V-notch specimen used in testing of notch effects...................................................... 3

Figure 5. Creep results for V-notch specimens with extensometers over the straight gage section and tested at (a) $800^{\circ} \mathrm{C}$ and (b) $900^{\circ} \mathrm{C}$.

Figure 6. Larson Miller plot, combining stress, temperature and rupture time of the completed $\mathrm{V}$-notch tests for comparison with other 617 creep rupture data. ${ }^{[6-18]}$

Figure 7. Optical micrographs from the $\mathrm{V}$-notch specimen tested at $800^{\circ} \mathrm{C}$ showing (a) the gage section, (b) the V-notch and (c) a higher magnification of the root of the V-notch

Figure 8. Optical micrographs from the V-notch specimen tested at $900^{\circ} \mathrm{C}$ showing (a) the gage section, (b) the V-notch and (c) a higher magnification of the root of the V-notch. A blue stain occurred at the bottom left in (c) due to bleed out of the electrolyte from the creep cavity after electropolishing.

Figure 9. Optical micrographs after electrochemical etch showing cracking occurring at the grain boundaries for both (a) the $800^{\circ} \mathrm{C}$ and (b) the $900^{\circ} \mathrm{C}$ tests.

Figure 10. Optical micrographs after electrochemical etch of the specimen tested at $800^{\circ} \mathrm{C}$, showing evidence of deformation (slip lines). (a) Lines are faintly visible in large grains in the straight gage section, (b) strongly evident at the tip of the V-notch, and (c) essentially non-existent along the sides of the v-notch away from the tip. 8 
Figure 11. FEA depicting stress across the V-notch specimens (applied stress scaled to $36 \mathrm{MPa}$, similar to the $900^{\circ} \mathrm{C}$ test), with (a) showing stress along the loading axis, (b) stress along the horizontal axis, and (c) stress along the out of plane axis.

Figure 12. FEA depicting stress across the small radius U-notch specimens (applied stress scaled to $36 \mathrm{MPa}$, similar the $900^{\circ} \mathrm{C}$ test), with (a) showing stress along the loading axis,

(b) stress along the horizontal axis, and (c) stress along the out of plane axis.

Figure 13. FEA depicting stress across the small radius U-notch specimens (applied stress scaled to $36 \mathrm{MPa}$, similar to the $900^{\circ} \mathrm{C}$ test), with (a) showing stress along the loading axis, (b) stress along the horizontal axis, and (c) stress along the out of plane axis. 10

Figure 14. FEA model of stress in the loading axis and optical micrograph showing the tip of the V-notch, (applied stress $80 \mathrm{MPa}$ at $800^{\circ} \mathrm{C}$ ). 10

\section{TABLES}

Table 1. Chemical Composition of the Alloy 617 Plate (Weight Percent) ................................................. 3

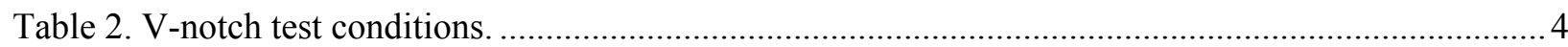

Table 3. Specimen measurements before and after creep test. ............................................................. 5 


\section{ACRONYMS}

ASME American Society of Mechanical Engineers

ASTM American Society for Testing and Materials

EBSD Electron backscatter diffraction

FEA Finite element analysis

INL Idaho National Laboratory

LMP Larson-Miller parameter

NRC Nuclear Regulatory Committee

VHTR very high temperature reactor 


\section{Progress Report on Alloy 617 Notched Specimen Testing INTRODUCTION}

Alloy 617 has been identified as the primary candidate material for the intermediate heat exchanger in very high temperature reactor (VHTR) concepts. This material exhibits good high temperature mechanical properties that are little affected by long time exposure to elevated temperatures. Recent testing in the U.S., in collaboration with Generation IV International Forum partners, and an extensive historical database have been used to develop a draft Code Case for qualification of Alloy 617 in Section III Division 5 of the American Society of Mechanical Engineers (ASME) Boiler and Pressure Vessel Code ${ }^{[1]}$ Code qualification of this material will allow it to be used in nuclear construction up to $950^{\circ} \mathrm{C}$ and up to 100,000 hours.

Extensive characterization of Alloy 617 high temperature properties has been carried out under laboratory conditions using uniaxial loading conditions. This testing has included examination of the mechanism responsible for steady state or minimum creep rate, measurement of creep rupture behavior over a wide range of stresses and temperatures, and examination of the relationship between onset of tertiary creep and cavity formation. Despite the fact that uniaxial testing is exclusively used in determining time dependent allowable stresses for ASME design purposes, relevant components operate under multi-axial stress states in service.

Multi-axial conditions that are representative of service conditions can be approximated in the laboratory using combinations of axial tension, torsion and pressure to tube specimens. This type of testing is complex and expensive. The multi-axial stress state can also be accomplished in notched bar testing where the loading is carried out in uniaxial creep testing frames. The constraint on radial deformation caused by the shank at the root of the notch produces a tri-axial stress state. However, this stress state is not uniform across the specimen. Despite this limitation, characterization of creep behavior of notched bars provides a valuable starting point for characterization of the effect of multi-axial loading. The effects of multi-axial stresses and geometric discontinuities such as notches, which may cause unexpected stress states, are some of the issues the Nuclear Regulatory Committee (NRC) has identified as important to address prior to the construction and operation of VHTRs. ${ }^{[2]}$ It is thus desirable to examine behavior of high temperature materials under multi-axial conditions, and compare the behavior to standard uniaxial laboratory tests.

In general, two different types of notched specimen have been used to explore the effects of a triaxial stress state on creep behavior; V-notch and U-notch. Typically, the V-notched specimens are used to establish multi-axial creep rupture properties, and the U-notch to examine multi-axial creep deformation response. ${ }^{[3]} \mathrm{A}$ V-notch specimen is specified in American Society for Testing and Materials (ASTM) Standard E292-09, as shown in Figure $1{ }^{[4]}$ This type of specimen was originally developed to describe the behavior of materials at the root of a thread. V-notch specimens are widely used to determine if a particular material at a particular temperature exhibits notch strengthening or weakening for a range of applications and its use is not restricted to fasteners. The ASTM standard limits the use of the v-notch specimen to evaluating rupture behavior. The presence of both a standard straight gage section and a $\mathrm{V}$-notch allow for comparison between a conventional creep test and a notched test. Location of ultimate failure is used to determine if the material is notch strengthening or notch weakening (due to failure in the straight gage section or the notch, respectively). The diameter of the straight gage section is the same as the diameter at the root of the notch. 
U-notch specimens are commonly used for notch/multi-axial stress effects on creep behavior, and the specimen designs are set in the code of practice by Webster ${ }^{[3]}$ to create double notched specimens, as diagramed in Figure 2. The double notch allows for the examination of the failure mechanism for one of the notches and the remaining, unfailed notch may be sectioned for metallographic analysis. The ratio of the diameter across the specimen at the root of the notch and the radius of the notch $\left(\mathrm{d}_{\mathrm{n} 0} / \mathrm{r}_{\mathrm{n} 0}\right.$ in Figure 3$)$ defines the severity of the notch and the resulting multiaxial stress state at the root of the notch. Figure 3 depicts various ratios. A ratio of 4.83 is the maximum that can be obtained and maintain a semi-circular notch.

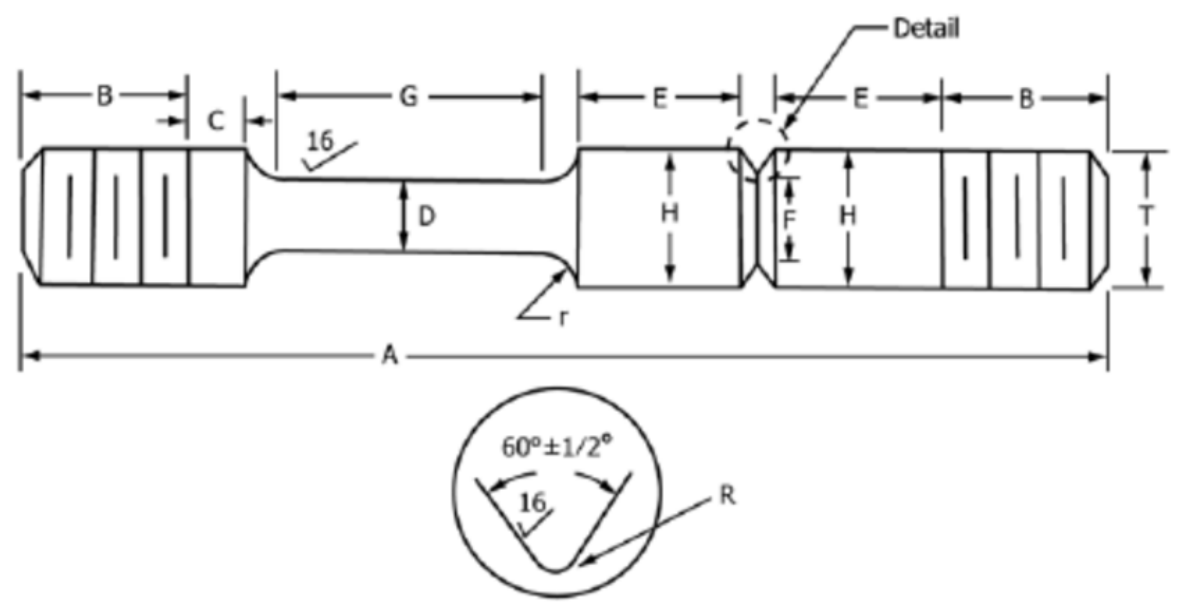

Figure 1. Creep rupture specimen commonly used during alloy development, featuring both a smooth and notched section. ${ }^{[4]}$

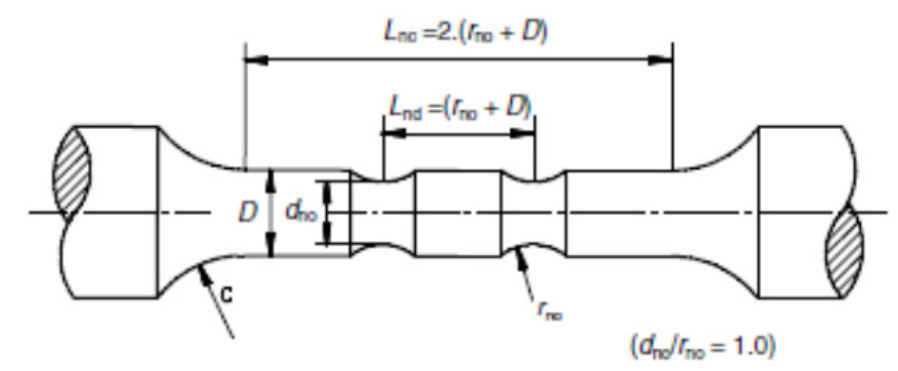

Figure 2. Schematic of the double notch Bridgman specimen. ${ }^{[3]}$

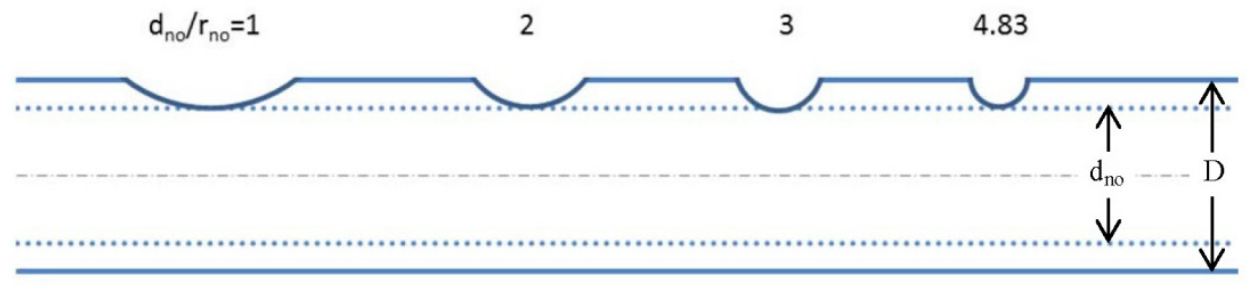

Figure 3. Schematic of the Bridgeman notches with varying $d_{n o} / r_{n o}$ ratios, all of which have a $D / d_{n o}$ value of $\sqrt{2}$. 


\section{EXPERIMENTAL PROCEDURE}

Specimens were machined with their longitudinal axes oriented along the rolling direction from a $37 \mathrm{~mm}$ thick plate provided by ThyssenKrup VDM (Heat \#314626). Composition is given in Table 1. This is the same material used in the Code Case studies and developing the steady state creep rate equations and the Larson-Miller equations to describe rupture behavior. The average grain size (as measured by the linear intercept method) is $150 \mu \mathrm{m}$. Carbide banding and stringers parallel to the rolling direction are also present in the as-received microstructure. The bands are approximately 100-300 $\mu \mathrm{m}$ wide, and the carbides appear to form on a prior grain structure, finer and unrelated to the present grain boundary structure. Outside of these banded regions, there are few secondary particles, with the exception of a small number of titanium nitrides.

Table 1. Chemical Composition of the Alloy 617 Plate (weight percent).

\begin{tabular}{ccccccccccccc}
\hline Ni & Cr & Co & Mo & Al & Ti & Fe & Mn & Cu & Si & C & S & B \\
\hline 54.1 & 22.2 & 11.6 & 8.6 & 1.1 & 0.4 & 1.6 & 0.1 & 0.04 & 0.1 & 0.05 & $<0.002$ & $<0.001$ \\
\hline
\end{tabular}

V-notch specimens were machined following the ASTM standard E292 ${ }^{[4]}$, shown in Figure 1. A small modification to the ASTM design was made to allow an extensometer to be connected to the specimen via grooves placed between the V-notch and the threads, the straight gage section and the V-notch, as well as the straight gage section and the threads, as seen in the actual specimen in Figure 4. This allows for displacement measures over the straight gage section, the V-notch, or the entire length of the specimen. In general for this series of tests, extensometer measurements were taken over the straight gage section or the V-notch. The diameter at the straight gage section and at the root of the V-notch is $6.4 \mathrm{~mm}$, similar to the sizes of straight gage creep specimens tested previously at INL, allowing for direct comparisons between the previous and current work. Two different U-notch specimens, following the design in Figure 2, are currently being machined, one with a $\mathrm{d}_{\mathrm{n} 0} / \mathrm{r}_{\mathrm{n} 0}$ ratio of 1 and the other with a ratio of 4.83 . The ratio of the outer and inner diameters of the specimen $\left(D / d_{n 0}\right.$ in Figure 3$)$ is arbitrary, however, a ratio of $\sqrt{2}$ has been used extensively with this specimen design and is recommended by the Code of Practice. ${ }^{[3]}$

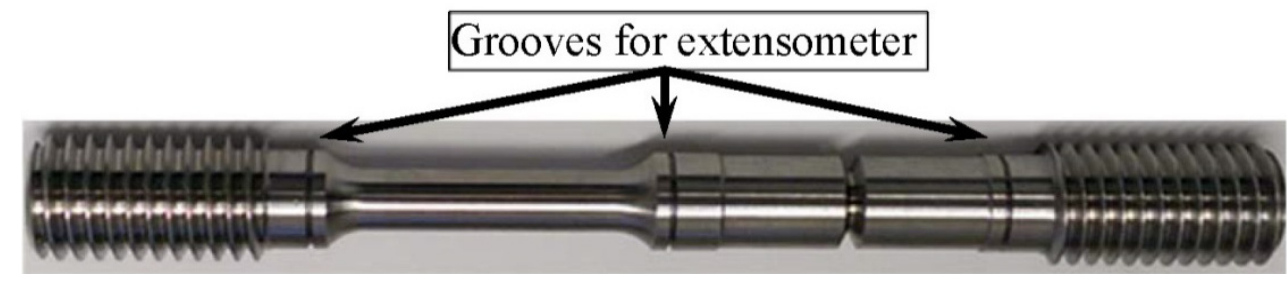

Figure 4. Actual V-notch specimen used in testing of notch effects.

Creep testing is being carried out over a range of temperatures, from $750^{\circ} \mathrm{C}$, up to $1,000^{\circ} \mathrm{C}$. Stresses were chosen such that tests completed within a reasonable amount of time ( 1000 hours) and that the tests matched conditions for conventional creep tests run previously at INL. A table of testing conditions that are expected to produce rupture in $\sim 1000 \mathrm{hrs}$ is given in Table 2 . The testing conditions have been modified since the original test plan ${ }^{[5]}$ in order to match prior work more closely. Current tests are at 750 , 800 , and $900^{\circ} \mathrm{C}$, with one test from both 800 and $900^{\circ} \mathrm{C}$ having been completed. Following rupture, specimens have been cross sectioned for micrographic analysis at both the straight gage section and the $\mathrm{V}$-notch. In addition to the metallographic preparation of cross sections, specimens were electrochemically polished and then electrochemically etched to reveal grain boundaries using perchloric acid at $0^{\circ} \mathrm{C}$ and at a potential of $24 \mathrm{~V}$ for electropolishing followed by electroetching at $9 \mathrm{~V}$ using a LectroPol 5 by Struers. 
Table 2. V-notch test conditions.

\begin{tabular}{|r|r|}
\hline \multicolumn{1}{|c|}{$\begin{array}{c}\text { Temperature } \\
\left({ }^{\circ} \mathrm{C}\right)\end{array}$} & $\begin{array}{c}\text { Stress for 1,000h } \\
(\mathrm{MPa})\end{array}$ \\
\hline 750 & 145 \\
\hline 800 & 80 \\
\hline 850 & 55.9 \\
\hline 900 & 36 \\
\hline 950 & 26.4 \\
\hline 1,000 & 20 \\
\hline
\end{tabular}

\section{RESULTS AND DISCUSSION}

Results exist currently for two $\mathrm{V}$-notch specimens run to failure, one at $800^{\circ} \mathrm{C}$ and the other at $900^{\circ} \mathrm{C}$. Both specimens failed in the straight gage section, suggesting notch strengthening for this material at these temperature. The creep behavior was compared to the prior tests and metallographic analysis has been performed on the cross sections of both specimens.

\section{Creep Results}

Creep curves for the V-notch specimens, with displacement measured with extensometers over the straight gage section, are shown for the tests at $800^{\circ} \mathrm{C}$ and $900^{\circ} \mathrm{C}$ in Figure 5. Also included in the figure are the curves from prior creep tests with straight gage specimens performed at INL with the same conditions. While time variations in time to rupture are observed, the variations are within expectations based on the variability of measured creep properties reported in the ASTM E139 standard for conducting creep tests of metallic materials. ${ }^{[6]}$ The Larson-Miller parameter (LMP) is a convenient way to compare creep-rupture data between samples at different loading stresses and temperatures. The LMP is defined as

$L M P=T\left(C+\log _{10}(t)\right)$

where $\mathrm{T}$ is the absolute temperature, $\mathrm{C}$ is the Larson-Miller constant and $\mathrm{t}$ is time to rupture. Figure 6 shows the results from the V-notch test compared to conventional creep rupture data collected at INL from a number of sources ${ }^{[7,8,9,10,11,12,13,14,15,16,17,18,19]}$ The presence of the notch did not noticeably affect the creep rupture life in alloy 617 at $800^{\circ} \mathrm{C}$ and $900^{\circ} \mathrm{C}$.

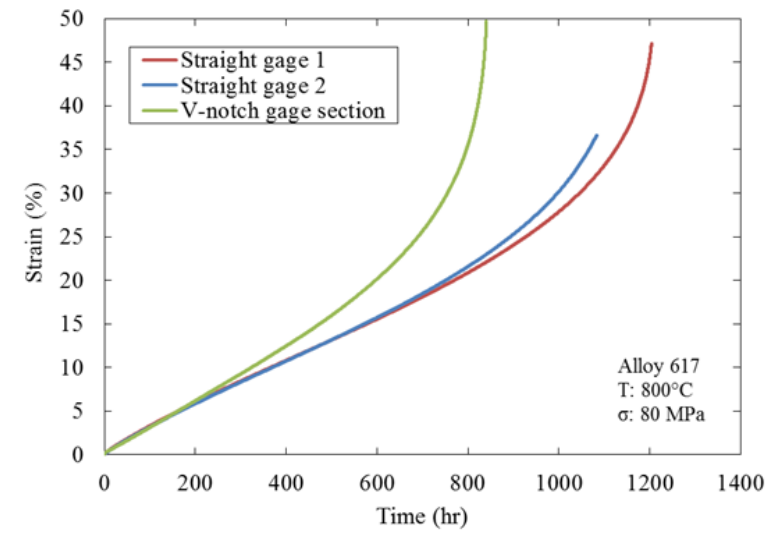

(a)

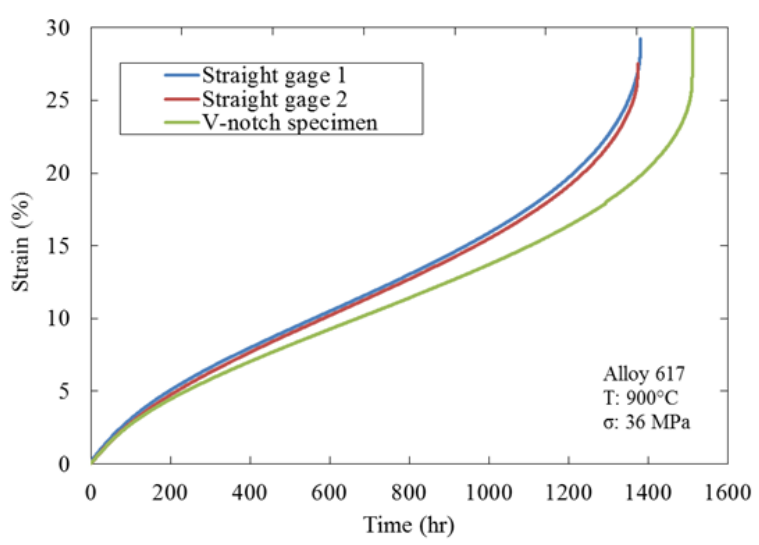

(b)

Figure 5. Creep results for V-notch specimens with extensometers over the straight gage section and tested at (a) $800^{\circ} \mathrm{C}$ and (b) $900^{\circ} \mathrm{C}$. 


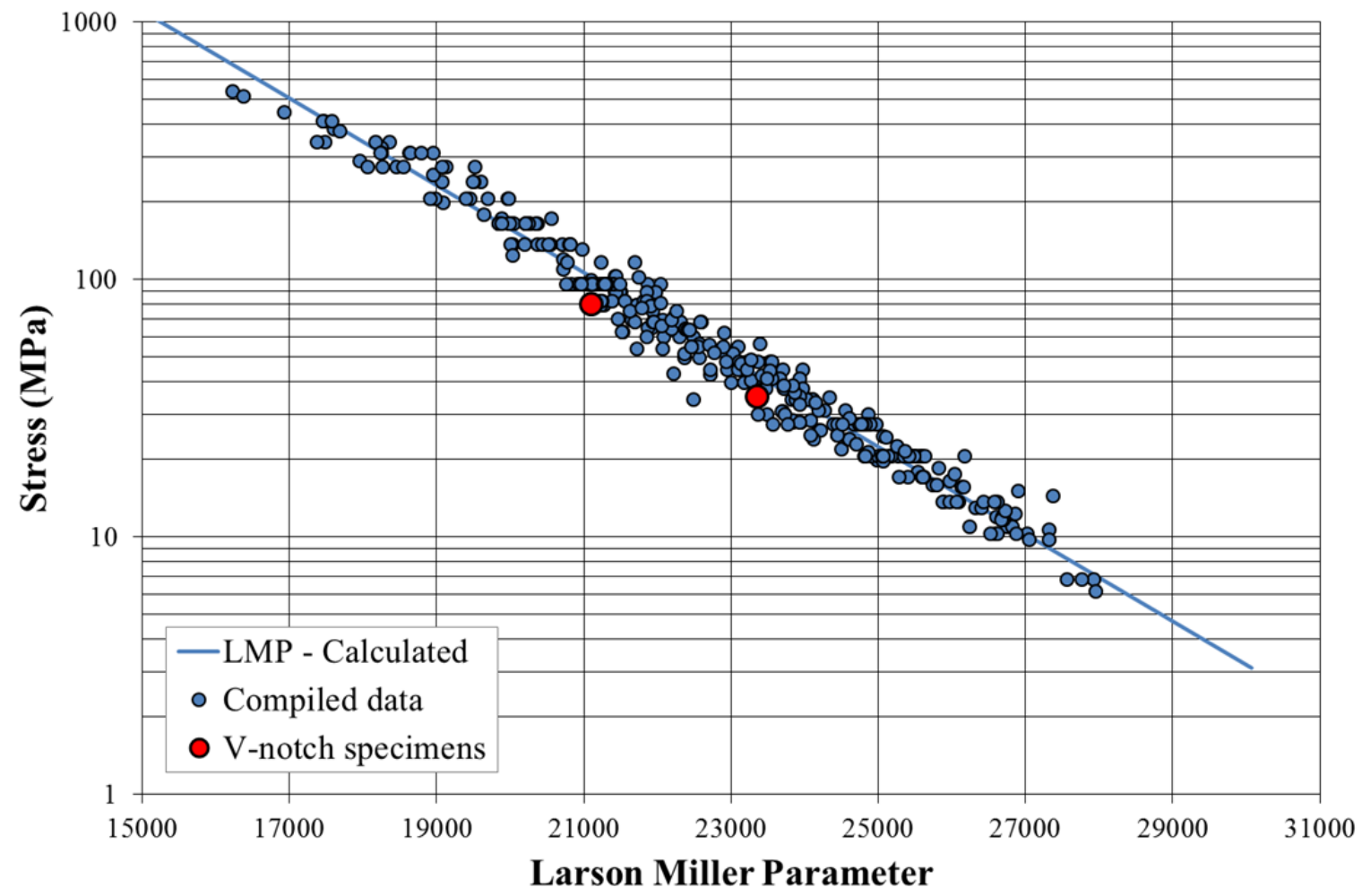

Figure 6. Larson Miller plot, combining stress, temperature and rupture time of the completed V-notch tests for comparison with other 617 creep rupture data. ${ }^{[6-18]}$

Most of the deformation during the creep test occurred in the straight gage section. As shown in Table 3, the diameters of the straight gage sections significantly decreased, whereas the diameter across the specimen at the root of the $\mathrm{V}$-notch essentially remained unchanged. This is not unexpected for material that undergoes significant plasticity. The geometric constraints of the notch restrict the radial contraction that would occur in the area near the tip of the notch when the specimen plastically deforms and elongates. The constraints on the deformation are from the wider shoulders adjacent to the notch which experience significantly lower levels of stress and thus are not inclined to deform and accommodate deformation at the tip notch. ${ }^{[20,21]}$ The straight gage section has no such constraints, and both elongates along the loading axis as well as radially contracts. As the test progressed, this means that an increased level of stress was experienced by the straight gage section, whereas the applied stress at the $\mathrm{V}$-notch remained the same, due to the nature of the constant load test and the changing dimensions of the specimen.

Table 3. Specimen measurements before and after creep test.

\begin{tabular}{|l|c|c|c|c|}
\hline \multirow{2}{*}{} & \multicolumn{2}{|c|}{$\mathbf{9 0 0}^{\circ} \mathbf{C ~ 3 6 M P a}$} & \multicolumn{2}{c|}{$\mathbf{8 0 0}^{\circ} \mathbf{C ~ 8 0 ~} \mathbf{M P a}$} \\
\cline { 2 - 5 } & Before & After & Before & After \\
\hline Gage diameter (mm) & 6.35 & 4.93 & 6.37 & 4.90 \\
\hline V-notch diameter (mm) & 6.35 & 6.37 & 6.26 & 6.29 \\
\hline
\end{tabular}

\section{Microscopy}

As stated previously, specimens tested at both 800 and $900^{\circ} \mathrm{C}$ failed in the straight gage section. Optical micrographic analysis show damage throughout the gage section, as seen in Figure 7a and Figure 8a. A small amount of damage is visible at the tip of the V-notch, shown in Figure $7 \mathrm{~b}$ and $\mathrm{c}$, and 
Figure $8 \mathrm{~b}$ and $\mathrm{c}$. The electrochemical etch confirmed that the cracking occurred at the grain boundaries (shown in Figure 9), as expected for creep cracking in this alloy. Additionally, the electrochemical etch revealed evidence of deformation and slip lines, as shown in Figure 10. These slip lines were only faintly visible in the straight gage section, showing up more clearly in larger grains (where larger amounts of deformation is likely to occur). The lines are clearly visible near the tip of the V-notch, though fade within 100-200 $\mu \mathrm{m}$. Along the length of the V-notch, there is essentially no visible evidence of deformation. Further analysis of the plasticity and deformation of the specimen, in particular around the $\mathrm{V}$-notch is planned through use of electron backscatter diffraction (EBSD). EBSD can reveal local misorientation in the lattice structure caused by dislocations (a result of deformation).

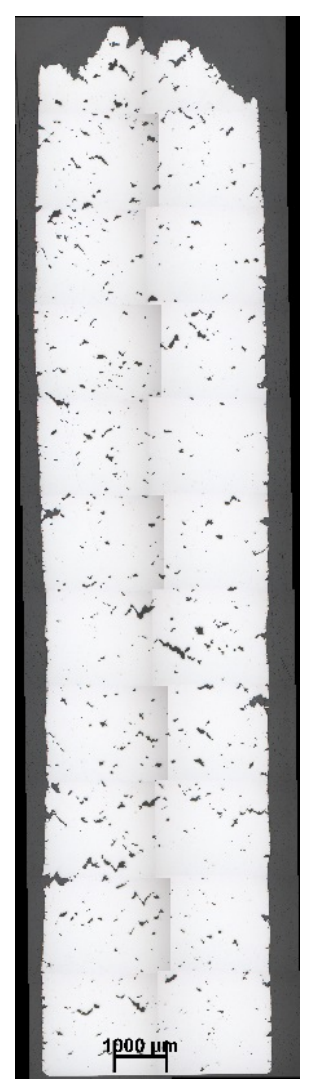

(a)

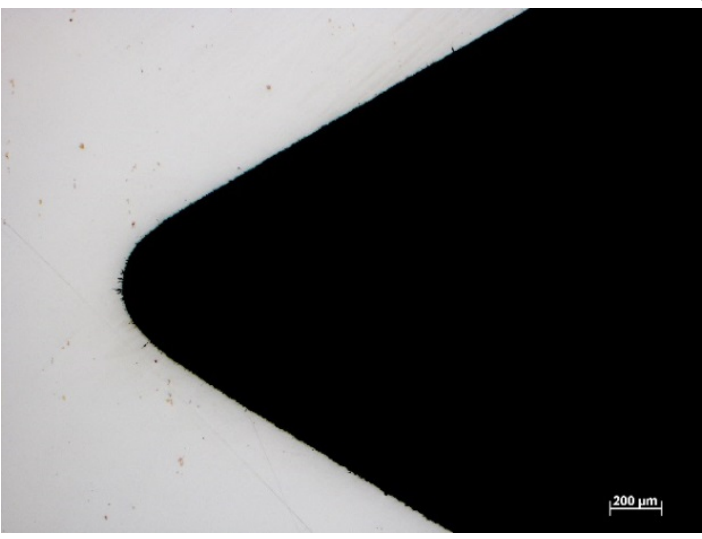

(b)

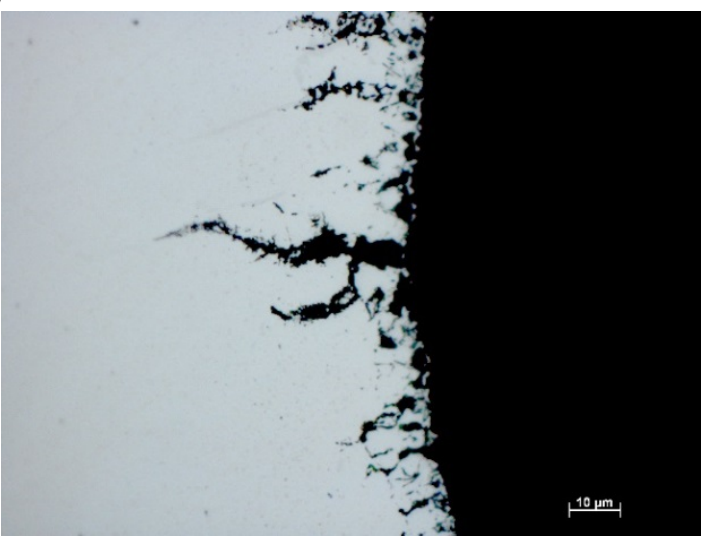

(c)

Figure 7. Optical micrographs from the $\mathrm{V}$-notch specimen tested at $800^{\circ} \mathrm{C}$ showing (a) the gage section, (b) the V-notch and (c) a higher magnification of the root of the V-notch 


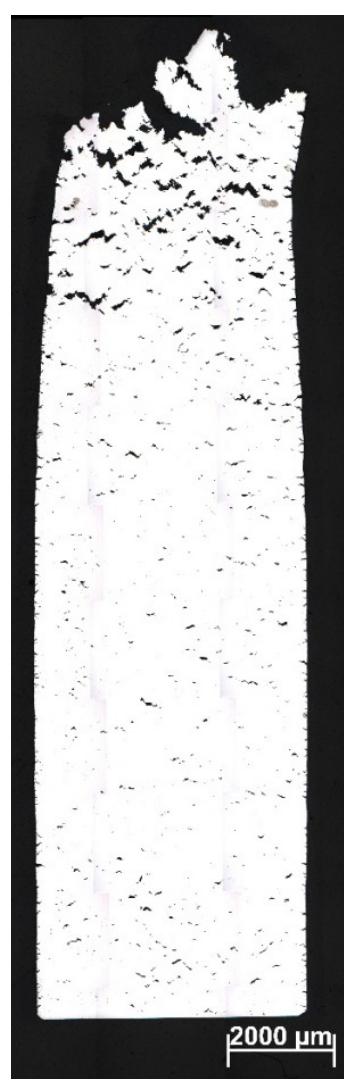

(a)

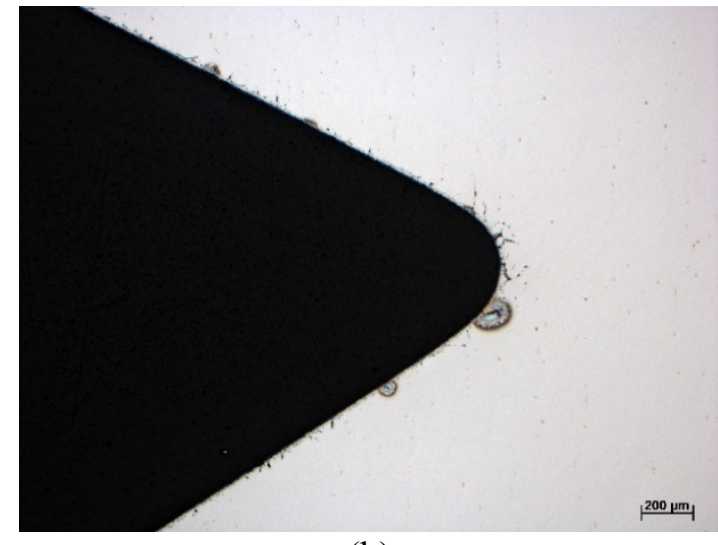

(b)

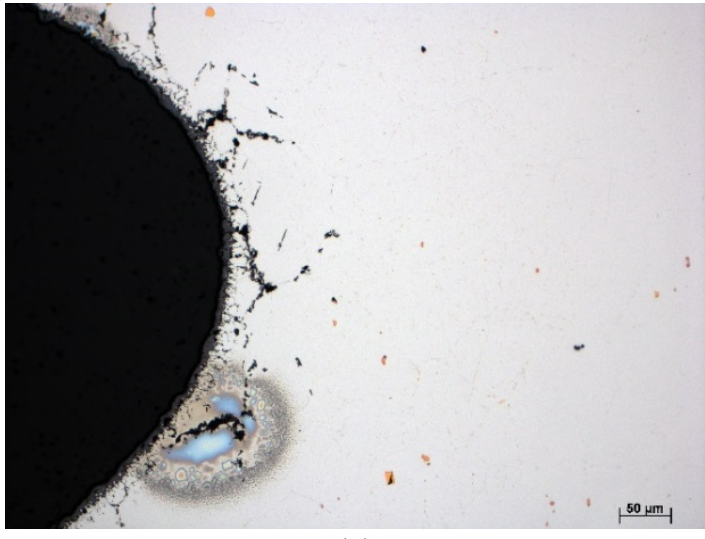

(c)

Figure 8. Optical micrographs from the $\mathrm{V}$-notch specimen tested at $900^{\circ} \mathrm{C}$ showing (a) the gage section, (b) the V-notch and (c) a higher magnification of the root of the V-notch. A blue stain occurred at the bottom left in (c) due to bleed out of the electrolyte from the creep cavity after electropolishing. 


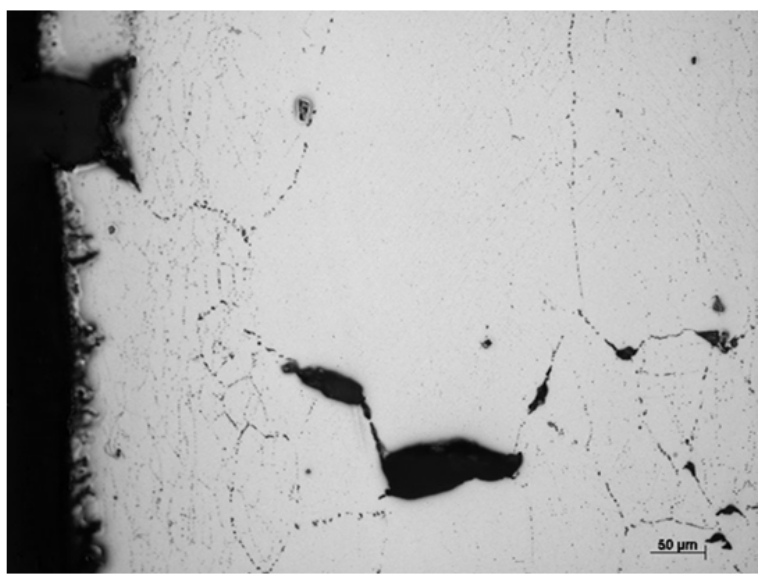

(a)

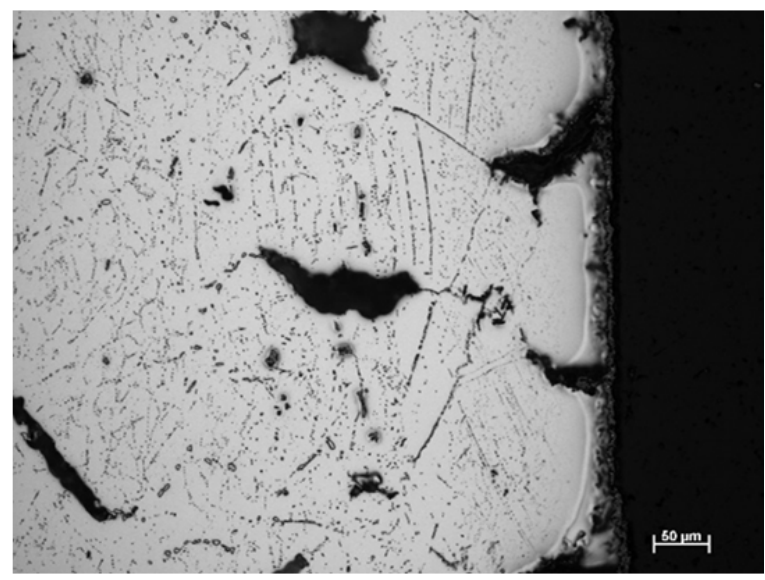

(b)

Figure 9. Optical micrographs after electrochemical etch showing cracking occurring at the grain boundaries for both (a) the $800^{\circ} \mathrm{C}$ and (b) the $900^{\circ} \mathrm{C}$ tests.

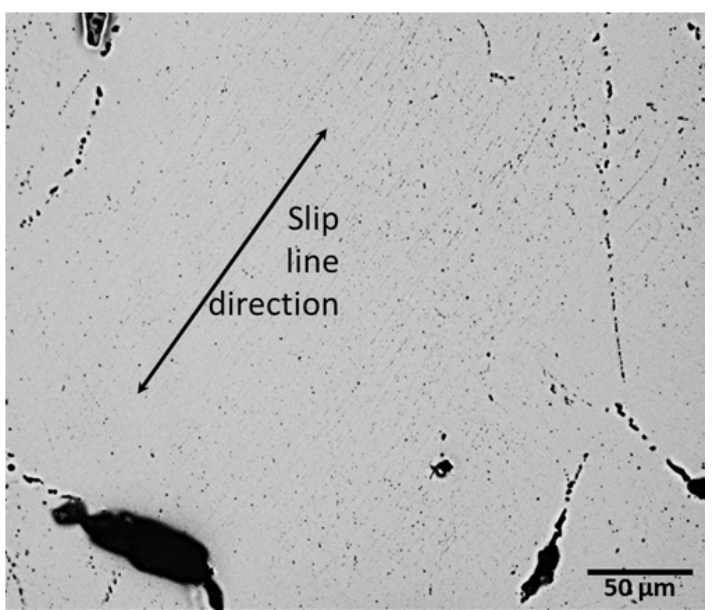

(a)

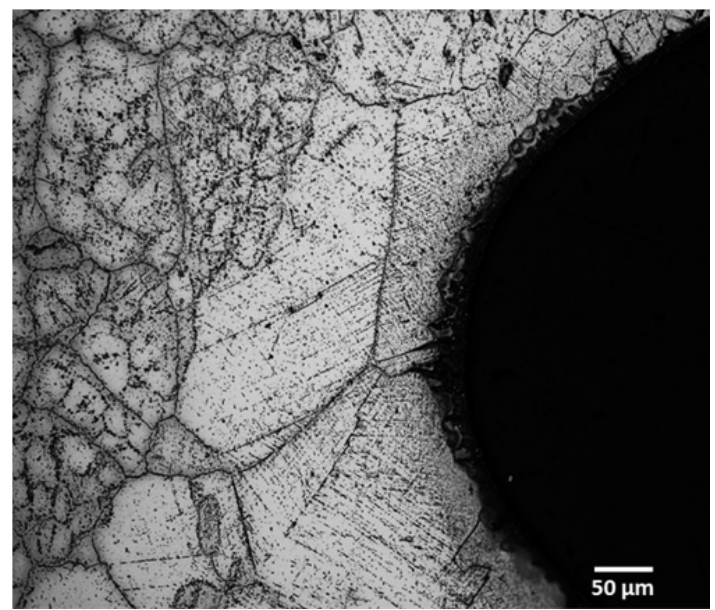

(b)

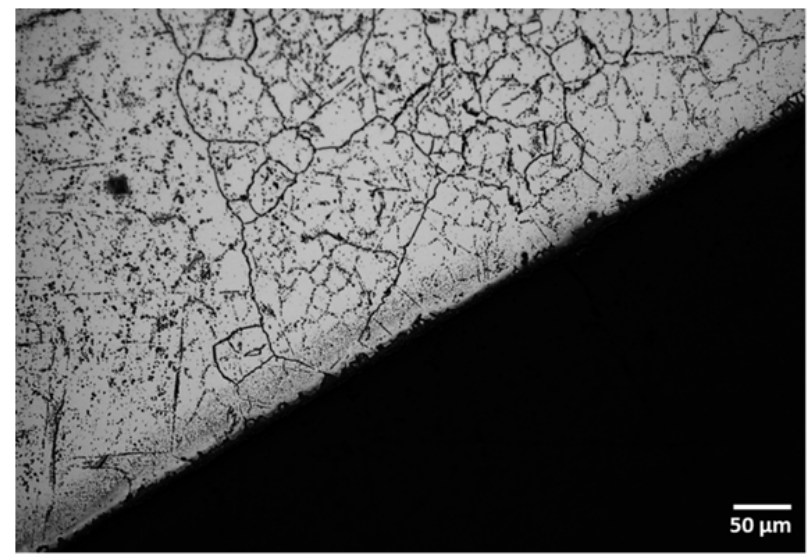

(c)

Figure 10. Optical micrographs after electrochemical etch of the specimen tested at $800^{\circ} \mathrm{C}$, showing evidence of deformation (slip lines). (a) Lines are faintly visible in large grains in the straight gage section, (b) strongly evident at the tip of the V-notch, and (c) essentially non-existent along the sides of the v-notch away from the tip. 


\section{Initial Stress States}

Finite element analysis (FEA) was performed using Abaqus software by Dassault Systems to determine initial stress states for all three notched type specimens (one V-notch, two distinct U-notch geometries, shown in Figure 11, Figure 12, and Figure 13, respectively). The FEA solutions do not take into account deformation and stress redistribution during creep, and so are only valid at the initial loading of the specimen. Multi-axial stress states are clearly shown for each notch type specimen, with the $\mathrm{V}$-notch specimens exhibiting the largest values, albeit over the smallest area, and the wider U-notch specimen showing lower values, though over a larger area (and nearly constant across the diameter of the specimen).

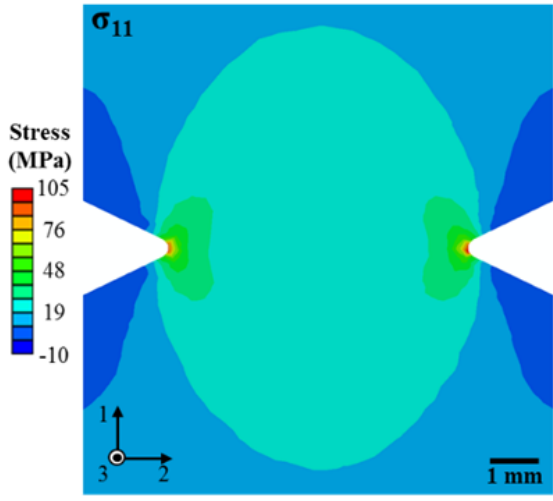

(a)

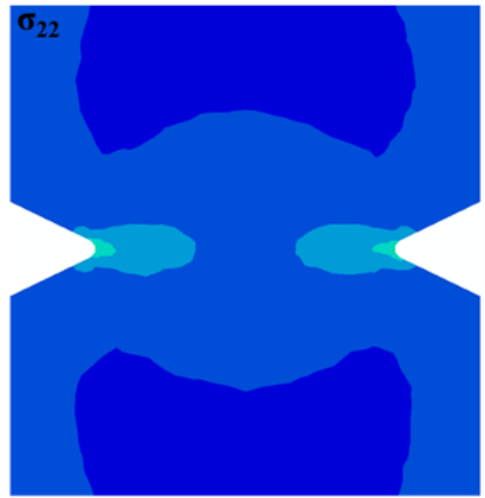

(b)

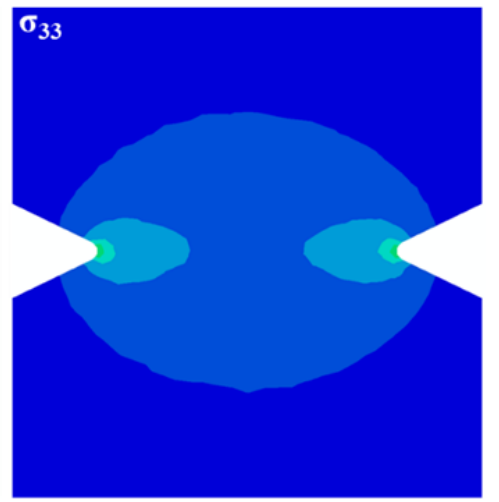

(c)

Figure 11. FEA depicting stress across the V-notch specimens (applied stress scaled to $36 \mathrm{MPa}$, similar to the $900^{\circ} \mathrm{C}$ test), with (a) showing stress along the loading axis, (b) stress along the horizontal axis, and (c) stress along the out of plane axis.

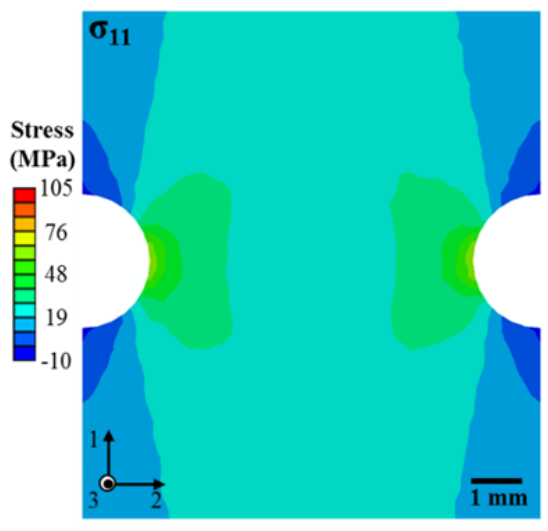

(a)

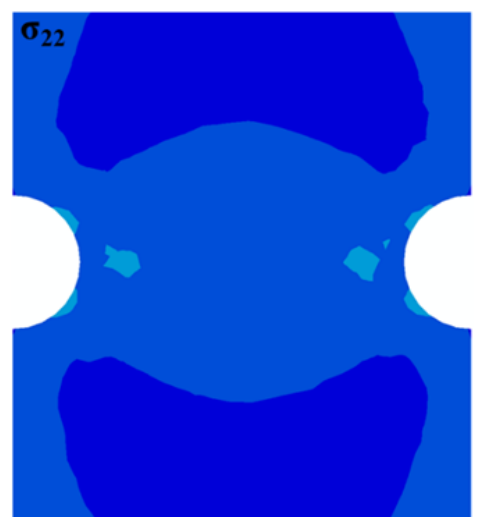

(b)

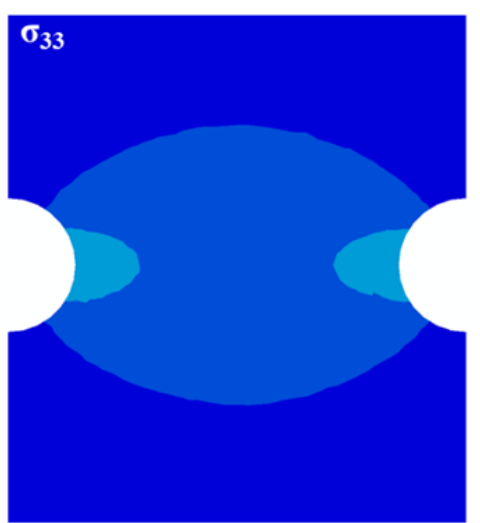

(c)

Figure 12. FEA depicting stress across the small radius U-notch specimens (applied stress scaled to $36 \mathrm{MPa}$, similar the $900^{\circ} \mathrm{C}$ test), with (a) showing stress along the loading axis, (b) stress along the horizontal axis, and (c) stress along the out of plane axis. 


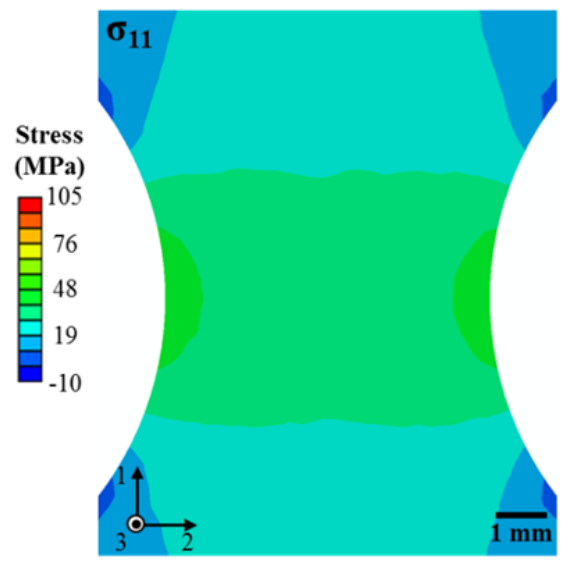

(a)

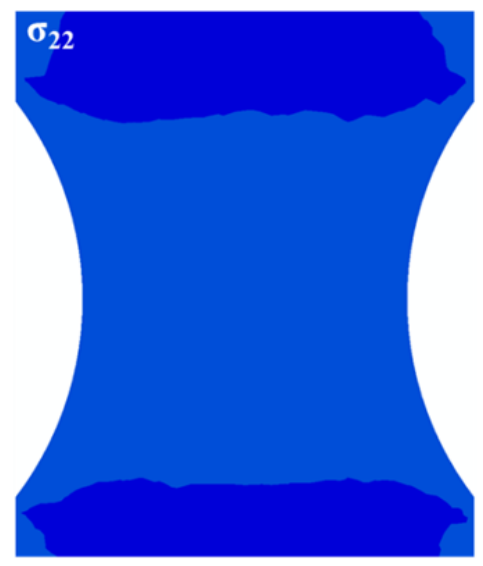

(b)

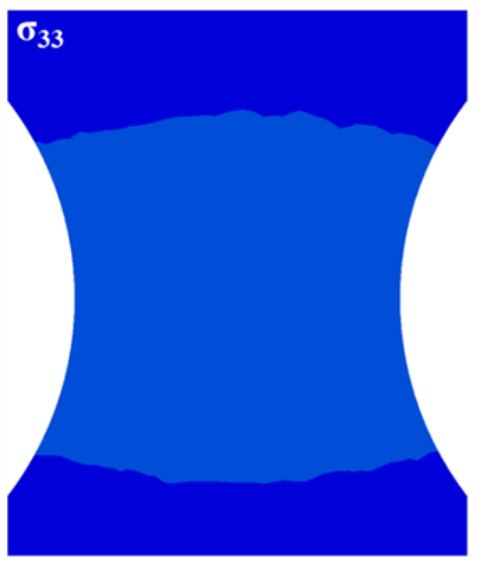

(c)

Figure 13. FEA depicting stress across the large radius U-notch specimens (applied stress scaled to $36 \mathrm{MPa}$, similar to the $900^{\circ} \mathrm{C}$ test), with (a) showing stress along the loading axis, (b) stress along the horizontal axis, and (c) stress along the out of plane axis.

The deformation observed in the V-notch specimen (Figure 10) is consistent with the expected stress states of the specimen, namely, the high stress near the tip of the notch, and the essentially non-existent stress along the sides of the notch. Furthermore, the area with the highest initial stress state is consistent with the small amount of damage observed at the tip of the V-notch (Figure 7c and Figure 8c), as shown side by side in

Figure 14 for the $800^{\circ} \mathrm{C}$ test specimen. The high stress states at the tip of the notch appear to cause some damage and deformation, however, the constraints by the wider areas of the specimen around the tip of the notch restrict significant changes in geometry, resulting in the observed unchanging diameter across the notched portion of the specimen. It is likely that the damage at the notch tip occurred early on in the test to relieve the high levels of stress concentrated there.

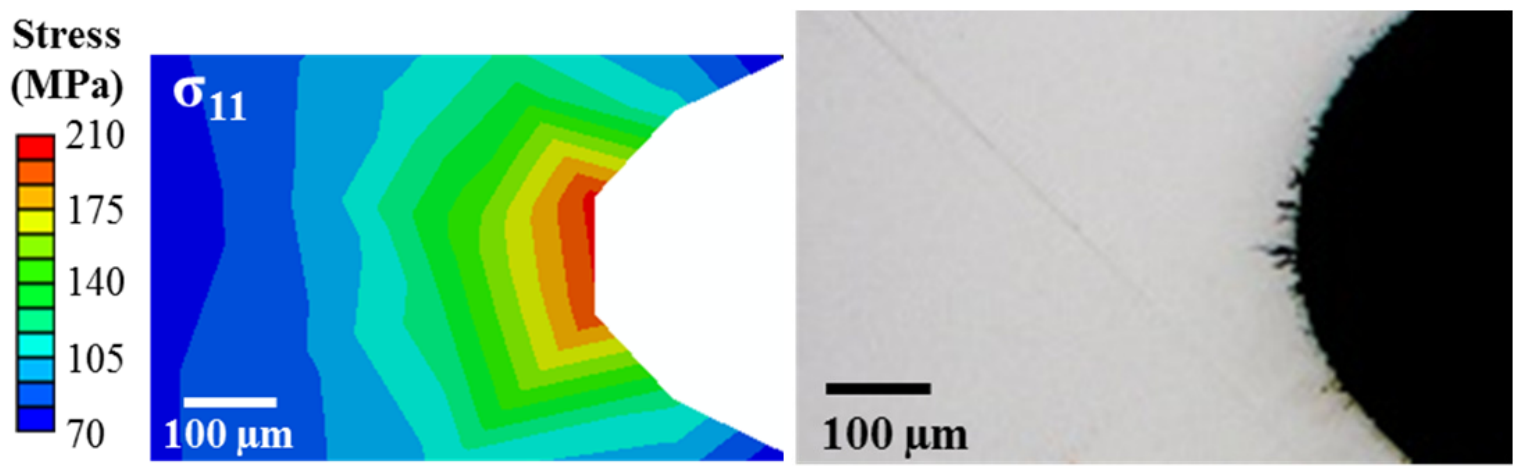

Figure 14. FEA model of stress in the loading axis and optical micrograph showing the tip of the V-notch, (applied stress $80 \mathrm{MPa}$ at $800^{\circ} \mathrm{C}$ ).

\section{Work in Progress}

Four additional V-notched specimen creep tests are currently loaded in the creep frames at INL. One at $750^{\circ} \mathrm{C}, 145 \mathrm{MPa}$, with the extensometer over the straight gage section. The remaining three have the extensometer over the $\mathrm{V}$-notch section to measure displacement in the notch, with one test at each temperature; $750^{\circ} \mathrm{C}, 800^{\circ} \mathrm{C}$ and $900^{\circ} \mathrm{C}$. 
The U-notched specimens (Figure 2) are in the process of being machined. When completed, they will be tested at similar conditions as the V-notched specimens. The double notched specimens will allow for examination of the mechanism of failure (at the failed notch) and the nature and extent of internal damage existing prior to failure (by metallographic analysis of the unfailed notch). The varying sizes (severities) of the U-notches will aid in understanding the effects of a wide range of stress states.

\section{CONCLUSIONS}

$\mathrm{V}$-notch specimen creep tests are currently running, with one test having been completed at both $800^{\circ} \mathrm{C}$ and $900^{\circ} \mathrm{C}$. At these temperatures, Alloy 617 is notch strengthening, as failure occurred in the straight gage section of the specimen. This is a result of the constraints on deformation caused by the wider areas around the tip of the V-notch, which experience significantly less stress than the area through the tip of the notch. The high concentration of stress at the tip of the V-notch does cause some damage and deformation, however, the unrestrained deformation in the straight gage section leads to an increasingly small cross section, and thus an increasingly level of stress, and ultimately to failure in the straight gage portion of the specimen. Additional testing is planned to evaluate the effects of the notch on creep rupture behavior at other temperatures, and U-notch specimens are currently being machined to evaluate creep properties in the presence of Multi-axial stress.

\section{REFERENCES}

[1] Wright, J., Draft ASME Boiler and Pressure Vessel Code Section III, Division 5, Section HB, Subsection B Code Case and Background Documentation. 2015.

[2] O'Donnell, W.J., Hull, A.B., and Malik, S. Structural integrity code and regulatory issues in the design of high temperature reactors. in Proceedings of the 4th International Topical Meeting on High Temperature Reactor Technology. 2008. Washington, DC.

[3] Webster, G.A., et al., A Code of Practice for conducting notched bar creep tests and for interpreting the data. Fatigue \& Fracture of Engineering Materials \& Structures, 2004. 27(4): p. 319-342.

[4] International, A., ASTM E292-09 Standard test method for conducting time-for-rupture notch tension tests of materials. 2009: West Conshohocken, PA.

[5] Wright, R.N., Test Plan for Evaluation of Notch Effects on High Temperature Rupture Behavior, in INL/MIS-15-37527. 2016: Idaho National Laboratory.

[6] International, A., ASTM E139-11 Standard test method for conducting creep, creep-rupture, and stress-rupture tests of metallic materials. 2011: West Conshohocken, PA.

[7] Huntington Alloys Data Package of Inconel 617.

[8] NIMS Inconel 617 Stress Rupture Data. 1975: Japan.

[9] Baldwin, D.H., Kimball, O.F., and Williams, R.A., (General Electric), Design Data for Reference Alloys: Inconel 617 and Alloy 800H, in US DOE file number HTGR-86-041. 1986.

[10] Cook, Creep properties of inconel-617 in air and helium at 800 and 1000 C. Nucl. Technol., 1984. 66: p. 283-288.

[11] Maitra, D., Special Metals Corporation private communication, J. Wright, Editor. 2015.

[12] Gentzbittel, J.M., Vincent, D., and Scheer N., Results of mechanical and microstructural characterization of alloys 617 and 230. Mechanical properties of TIG welded 617, in CEA DTH/DL2007/80. 2007. 
[13] Kim, W.-G., et al., Creep behavior for alloy 617 in air at 950 C. Mater. Sci. Forum, 2010. 654-656: p. 508-511.

[14] Kim, W.-G., et al., Creep behaviour and long-term creep life extrapolation of ally 617 for a very high temperature gas-cooled reactor. Trans. Indian Inst. Met., 2010. 63(2-3): p. 145-150.

[15] Kim, W.-G., et al., Creep oxidation behaviour and creep strength prediction for alloy 617. Int. J. Press. Vessels Pip., 2010. 87: p. 289-295.

[16] Kim, W.-G., et al. Investigation of creep rupture properties in air and He environments of alloy 617 at 800 C. in Proceedings of HTR 2014. 2014. Weihai, China.

[17] McCoy, H.E. and King, J.F., (Oak Ridge National Laboratory), Mechanical Properties of Inconel 617 and 618, in ORNL/TM-9337. 1985.

[18] Natesan, K., et al., Creep testing of alloy 617 and A508/533 base metals and weldments, in ANL/EXT-12/36. 2012: Argonne National Laboratory.

[19] Wright, J. and Lillo, T., (Idaho National Laboratory), Progress Report on Alloy 617 Time-Dependent Allowable Stresses, in INL/EXT-15-35640, Revision 1. 2015.

[20] Bridgman, P.W., Studies in large plastic flow and fracture with special emphasis on the effects of hydrostatic pressure. Metallurgy and metallurgical engineering series. 1952: McGraw. 362p.illus.,bibl.

[21] Hertzberg, R.W., Deformation and fracture mechanics of engineering materials. 1989: Wiley. 